\title{
Waves affect predator-prey interactions between fish and benthic invertebrates
}

\author{
Friederike Gabel - Stefan Stoll • Philipp Fischer • \\ Martin T. Pusch • Xavier-François Garcia
}

\begin{abstract}
Little is known about the effects of waves on predator-prey interactions in the littoral zones of freshwaters. We conducted a set of mesocosm experiments to study the differential effects of ship- and wind-induced waves on the foraging success of littoral fish on benthic invertebrates. Experiments were conducted in a wave tank with amphipods (Gammarus roeseli) as prey, and age-0 bream (Abramis brama, B0), age-0 and age-1 dace (Leuciscus leuciscus, D0 and D1) as predators. The number of gammarids suspended in the water column was higher in the wave treatments compared to a no-wave control treatment, especially during pulse waves mimicking ship-induced waves in comparison to continuous waves mimicking windinduced waves. The resulting higher prey accessibility in the water column was differently exploited by the three types of predatory fish. D0 and D1 showed significantly higher foraging success in the pulse wave treatment than in the continuous and control treatments. The foraging success of D0 appears to be achieved more easily, since
\end{abstract}

Communicated by Craig Osenberg.

F. Gabel and S. Stoll contributed equally to this work.

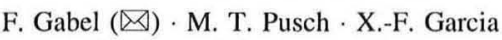

Leibniz-Institute of Freshwater Ecology and Inland Fisheries

Berlin, Mueggelseedamm 301, 12587 Berlin, Germany

e-mail: gabel@igb-berlin.de

S. Stoll

Limnological Institute, University of Konstanz,

78457 Constance, Germany

e-mail: Stefan.Stoll@uni-konstanz.de

P. Fischer

Alfred-Wegener-Institute for Polar and Marine Research, Biologische Anstalt Helgoland, Kurpromenade 201, 27498 Helgoland, Germany significantly higher swimming activity and more foraging attempts were recorded only for D1 under the wave treatments. In contrast, B0 consumed significantly fewer gammarids in both wave treatments than in the control. Hence, waves influenced predator-prey interactions differently depending on wave type and fish type. It is expected that regular exposure to ship-induced waves can alter littoral invertebrate and fish assemblages by increasing the predation risk for benthic invertebrates that are suspended in the water column, and by shifting fish community compositions towards species that benefit from waves.

Keywords Ship- and wind-induced waves .

Hydrodynamic disturbance - Invertebrate detachment .

Foraging success

\section{Introduction}

Predation is a key process shaping terrestrial and aquatic communities and has major consequences on ecosystem functioning (Macan 1977; Sih et al. 1985; Schofield et al. 1988). Predator-prey interactions are influenced by environmental stresses such as extreme temperatures, desiccation, habitat modification, and harsh hydrodynamic conditions (Sih et al. 1985). These environmental stresses have complex effects that differ among predator species. For example, increasing flow velocity reduces the predation success of invertebrate predators due to either decreased predator-prey encounters (Malmqvist and Sackmann 1996; Hart and Merz 1998; Powers and Kittinger 2002), an altered ability of predators to chemically detect prey (Powers and Kittinger 2002), or a reduction in the prey capture success of predators (Peckarsky et al. 1990; Hart and Finelli 1999). Conversely, increased flow velocities can favour predation 
rates of lotic fish species by increasing food accessibility due to higher drift rates of benthic invertebrates (Elliott 1973; but see Palmer 1988). However, the benefit to fish is complex and depends on the balance between energy costs and the benefits of food intake. For example, the growth of Atlantic salmon (Salmo salar) increased at high flow velocities due to higher food accessibility (invertebrate drift), but also increased at low flow velocities due to lower swimming costs in comparison to intermediate flow velocities (Blanchet et al. 2008).

Most studies on the effects of hydrodynamic stress have been performed in lotic ecosystems. However, hydrodynamic stress also occurs in lakes, particularly those used for commercial or recreational navigation, where wind- as well as ship-induced waves can occur. Wind-induced waves are generated continuously and occur mainly on shores exposed to dominant winds. Ship-induced waves exhibit a pulse pattern generated by the passage of ships, and can also affect shores that are naturally protected from wind.

The hydrodynamic disturbances caused by wind- or ship-induced waves can dislodge littoral invertebrates from their habitats (Winnell and Jude 1991; Commito et al.1995; Bishop 2008; Gabel et al. 2008). Consequently, a higher risk of an invertebrate being preyed upon can be expected. However, waves may also affect the foraging success of fish predators by influencing swimming performance, displacement, and community shifts (Arlinghaus et al. 2002; Wolter and Arlinghaus 2003; Wolter et al. 2004; Stoll et al. 2010). Stoll and Fischer (2010) distinguished three different reaction types of juvenile cyprinids to pulse waves. While small and fusiform fish (low body depth to fork length ratio) showed increased metabolic rates and somatic growth, small and deep-bodied fish (high body depth to fork length ratio) decreased their metabolic rates and grew less. Larger fish, irrespective of their body shape, showed increased metabolic rates and reduced somatic growth, suggesting that they allocated more energy to swimming activity when exposed to wave action.

In the present study, we experimentally investigated how predator-prey interactions are influenced by hydrodynamic disturbances associated with pulse waves (mimicking ship-induced waves) and continuous waves (mimicking wind-induced waves). Following Stoll and Fischer (2010), we used the same three fish types that differ in their susceptibilities to wave disturbance in simulated waves. By quantifying the foraging attempts, foraging success and swimming activity of fish predators and the suspension rate of their benthic prey, we tested the following hypotheses: (1) waves increase prey accessibility, especially under pulse waves, as sudden disturbances will detach more individuals; (2) smaller fusiform fish benefit more from hydraulic stress than larger or deep-bodied fish, and; (3) ship-induced waves have a stronger impact on predator-prey interactions than wind-induced waves, as fish can also forage after a wave passage when their prey is still suspended.

\section{Materials and methods}

\section{Experimental design}

Experiments were conducted in a $10 \mathrm{~m}$ long, $1 \mathrm{~m}$ wide, and $1 \mathrm{~m}$ high wave tank with a glass side wall located at the Limnological Institute of the University of Constance. Near-harmonic waves were created by a pneumatic wave generator placed at one end of the wave tank (Scheifhacken 2006). The waves propagated horizontally for $5.2 \mathrm{~m}$ before reaching an artificial shore (slope inclination 25\%) covered with stones and gravel.

A cage was located on a horizontal plane in the middle of the shore. It had base dimensions of $1 \mathrm{~m} \times 0.5 \mathrm{~m}$ and was immersed in water to a depth of $0.4 \mathrm{~m}$, providing a total volume of $0.20 \mathrm{~m}^{3}$. The bottom of the cage consisted of sand topped with a thin layer of pebbles ( $\varnothing 4-8 \mathrm{~mm}$ ), as often observed along natural lake shores. To prevent invertebrates and fish from escaping, the walls of the cage were covered with a wire net with a mesh size of $1 \mathrm{~mm}$. Water temperature was kept constant $\left(18.7 \pm 0.7^{\circ} \mathrm{C}\right.$, mean $\pm \mathrm{SD}$ ) during the duration of the study by using a recycling system between the wave tank and a separate heating tank.

Three different wave treatments were run: (1) a continuous wave treatment mimicking continuous wind waves; (2) a pulse wave treatment mimicking ship passages, and; (3) a control treatment without waves. The pulse wave treatment consisted of $1 \mathrm{~min}$ of waves (the wave phase) followed by three minutes without waves (pause phase). Wave hydrodynamic properties were measured inside the cage with an acoustic Doppler velocimeter (ADV, Nortek, Rudd, Norway) at four positions: the front (near side of the wave machine) and rear part (far side of the wave machine) of the cage at both 6.5 and $16.5 \mathrm{~cm}$ above the bottom. These depths correspond to the closest location to the bottom within the working range of the ADV and to the furthest location to the bottom that was still under water during wave troughs. To determine the current velocity, wave period and wavelength, 100 wave passages were evaluated at each location. Because no significant differences were found in the wave characteristics at the four locations (ANOVA, $P>0.05$ for all tests), we assumed a homogeneous wave field inside the cage. Both continuous and pulse waves had an orbital velocity $u$ of $18.5 \mathrm{~cm} \mathrm{~s}^{-1}$, a wave period $T$ of $1.3 \mathrm{~s}$, and a wave height $H$ of $12 \mathrm{~cm}$, resulting in an energy flux $E_{\mathrm{F}}$ of $21 \mathrm{~W} \mathrm{~m}^{-1}$ inside the cage. Energy flux is assumed to be an appropriate measure of the 
ecological relevance of waves (Hofmann et al. 2008). Thus, the wave parameters corresponded to the natural range of energy fluxes (13-31 $\mathrm{W} \mathrm{m}^{-1}$ ) as measured for ship waves at the shores of Lake Constance during summer (Hofmann et al. 2008). As the wave energy fluxes of the flume were well within the range of natural energy fluxes, and as wave orbital velocities were lower in the flume, the effects of the flume waves should not overestimate effects present in the field. Possible small-scale turbulences generated by the cage or the net were neglected, as observed suspension rates of invertebrates are comparable to those recorded in other flume (Gabel et al. 2008) and field (Gabel et al., unpublished data) experiments that did not use cages.

\section{Predator and prey species}

The amphipod Gammarus roeseli Gervais (Crustacea) was used as the prey species because it is widespread and common in European lakes and rivers and is a preferred prey for many benthivorous fish species. Furthermore, G. roeseli is sensitive to wave-induced disturbances, as individuals are detached from their habitat if exposed to waves (Gabel et al. 2008). G. roeseli decreases its activity during the daytime to avoid predation and hides in crevices and interstitial spaces between coarser sediment (e.g. Starry et al. 1998), but does not burrow in the sand. Individuals used for the experiments were caught with a hand net on a moderately wave-exposed mixed sand and gravel shore at Lake Constance 1 week prior to each experiment and stored at $18^{\circ} \mathrm{C}$ in $20 \mathrm{~L}$ flow-through lake water aquariums. To comply with predator feeding requirements, only individuals of length 5-7 $\mathrm{mm}$ were used for experiments. All predator types fed on and were accustomed to this prey size.

Age-0 and age-1 dace (Leuciscus leuciscus, D0 and D1) and age -0 bream (Abramis brama, B0) were the predators. Dace and bream are common in central European lakes and rivers. Bream primarily live in lakes and slow-flowing reaches of rivers, and dace live in streams, rivers, and oligotrophic lakes (Kottelat and Freyhof 2007). Both species feed on gammarids (Hellawell 1974; Hine and Kennedy 1974; Goldspink 1978), picking individual prey items selectively at a young age (Bryazgunova 1979; Weatherley 1987), and hunting visually during dawn and daytime (Backiel and Zawiska 1968; Crowden and Broom 1980). Age-0 dace and bream form large shoals with densities of up to 20 ind. $\mathrm{m}^{-2}$ (dace) or 15 ind. $\mathrm{m}^{-2}$ (bream) in Lake Constance (Stoll, unpublished data).

The three types of fish were chosen as each represented a distinct reaction type with respect to somatic growth and metabolic rate when subjected to previous experimental wave treatments (Stoll and Fischer 2010). B0 in the present study corresponds to B0-L in Stoll and Fischer. Individuals of D0 [mean \pm SD: $70.44 \pm 6.7 \mathrm{~mm}$ fork length (FL), $2.5 \pm 0.7 \mathrm{~g}$ wet weight (WW)] were caught in Lake Constance by beach seining 1 week before the experiments. D1 (106.1 $\pm 7.5 \mathrm{~mm}$ FL, $8.5 \pm 1.8 \mathrm{~g} \mathrm{WW})$ individuals were caught by beach seining 1 year before the experiment and kept in aquariums for the year. B0 $(67.6 \pm 9.4 \mathrm{~mm}$ FL, $2.3 \pm 1.1 \mathrm{~g} \mathrm{WW})$ were bred at the Limnological Institute using parents caught from Lake Constance, as fish-holding history does not influence the susceptibility of these fish categories to waves (Stoll et al. 2008). The three fish types were kept in separate $300 \mathrm{~L}$ flow-through lakewater aquaria at $18^{\circ} \mathrm{C}$ and fed ad libitum with living $G$. roeseli daily. To ensure homogeneous hunger levels, the fish were starved for $24 \mathrm{~h}$.

\section{Experimental protocol}

Experiments followed a crossed design between three types of fish (D0, D1, B0) and three wave treatments (control treatment without waves, continuous waves, pulse waves). Each trial lasted for $60 \mathrm{~min}$ and each treatment was replicated three times. Five individuals per fish type were used per trial and placed in the cage 1 day before to start the trial. To acclimate the fish to the start of the wave generator and to experimental waves, fish individuals were subjected to $5 \mathrm{~min}$ wave pulses every $15 \mathrm{~min}$ for $3 \mathrm{~h}$ in the morning of the trial. One hour before the trial, a Perspex cylinder corresponding to $10 \%$ of the bottom surface of the cage $(\varnothing 25 \mathrm{~cm})$ was placed in the cage and filled with 100 $G$. roeseli individuals. The selected density of gammarids corresponds to densities found in the eulittoral zone of Lake Constance (Mörtl and Rothhaupt 2003). After 1 h, the gammarids had settled to the bottom substrate. The cylinder was removed, and a wave treatment was started. At the end of each trial, the fish were removed and immediately killed with $2 \mathrm{mg} \mathrm{L}^{-1}$ trichloromethyl-propanol (Carl Roth, Karlsruhe, Germany). Each fish gut was dissected under a stereo microscope (Stemi, Carl Zeiss AG, Jena, Germany), and the number of ingested gammarids per fish was counted. Gammarids remaining in the wave tank were removed before the next trial.

The number of gammarids suspended in the water column was calculated from high-resolution photos taken with a digital SLR camera (Eos 30D, Canon, Krefeld, Germany) placed $1 \mathrm{~m}$ in front of the glass side wall of the arena. To achieve high-resolution images, only one-third of the cage volume was photographed. Based on the number of suspended gammarids in the surveyed area, the total number of suspended gammarids was extrapolated for the full cage. Three series of three photos were shot at four intervals during the trials. The time lag between consecutive photos in one series was $0.5 \mathrm{~s}$, and the time lag between the different series within one interval was at least $1 \mathrm{~min}$. The 
middle photos of each series were used to count suspended gammarids. The first and the last photo in the series were only used to resolve ambiguities on the middle photo in order to detect movements of gammarids. To test for temporal variability in gammarid suspension throughout the trials, photos were taken at four time intervals. During the first 4 min after the removal of the Perspex cylinder, there was a massive dispersal of gammarids in the cage. These first $4 \mathrm{~min}$ were then excluded from the analysis, and the remaining time was evenly divided into three intervals (minutes 5-23, 24-42, and 43-60).

Fish behaviour was recorded by filming trials with a camcorder (NV-GS 280, Panasonic, Hamburg, Germany) placed adjacent to the SLR camera. We assessed fish swimming activity in three equally sized adjacent virtual fields within the cage. The average number of field changes per minute and per fish was counted during three 5-min intervals $(1-5,31-35$, and $56-60 \mathrm{~min})$. The time interval split was different for fish and gammarids because the fish were not affected by the removal of the cylinder at the beginning of the experiments.

Foraging attempts were measured by counting the number of snaps for prey made by each fish, and expressed as the number of snaps per minute and per fish during the swimming activity intervals.

\section{Data analysis and statistics}

To evaluate differences in the number of suspended gammarids among time intervals and wave treatments, we used a full-factorial two-way ANOVA. The ANOVA analysis confirmed significant differences in the number of suspended gammarids between the first $4 \mathrm{~min}$ and the remaining duration of the trial: all four intervals: $R^{2}=0.49$ [wave treatment $(d f=2, \quad F=5.6, \quad P=0.005)$, time interval $(d f=3, \quad F=37.9, \quad P<0.001)$, wave treatment $\times$ time interval $(d f=6, F=2.4, P=0.029)$ ]; only intervals from minute 5-60: $R^{2}=0.20$ [wave treatment $(d f=2, \quad F=6.3, \quad P=0.003)$, time interval $(d f=2$, $F=2.1, P=0.129$ ), wave treatment $\times$ time interval $(d f=4, F=1.0, P=0.435)]$. Therefore, data for the first 4 min were excluded from further data processing. For the remaining intervals, the number of suspended gammarids showed no significant differences among time intervals. Data for these three intervals were pooled for Student's post hoc tests on the effect of wave treatment.

A full-factorial two-way ANOVA was used to assess differences in swimming activity and foraging attempts among wave treatments and among time intervals. Each type of fish was tested separately. The swimming activity did not differ significantly among the time intervals for any of the fish (D0: $P=0.69$; D1: $P=0.19$; B0: $P=0.82$ ), and there was no significant interaction between time interval and wave treatment (D0: $P=0.89 ; \mathrm{D} 1: P=0.93$; B0: $P=0.83$ ). Similar results were obtained for foraging attempts among time intervals (D0: $P=0.09$; D1: $P=0.97 ;$ B0: $P=0.93$ ) and regarding an interaction between time interval and wave treatment (D0: $P=0.15$; D1: $P=0.55$; B0: $P=0.61)$. Therefore, we removed time interval as a factor from the analyses and left wave treatment as the sole factor. Student's post hoc tests were used for further analysis of differences in swimming activity and foraging attempts among wave treatments.

A full-factorial two-way ANOVA was used to detect effects of wave treatment, fish type and interactions between wave treatments and fish types on foraging success, swimming activity and foraging attempts.

In further analyses, differences in foraging success, swimming activity and foraging attempts among wave treatments were analyzed for each type of fish separately using one-way ANOVAs followed by a Student's post hoc test. Paired-sample $t$ tests were then used to check for differences between the wave phase and the pause phase within the pulse wave treatment. Deviation of the data from normality and homogeneity of variances were tested for using Shapiro-Wilk and Levene tests before any statistical analyses; these were performed using the software JMP 4.0 (SAS Institute Inc., Cary, NC, USA). Significance was evaluated at $P=0.05$.

\section{Results}

Impact of waves on prey

Significantly more gammarids were detached during the pulse wave treatment compared to the control treatment (Fig. 1). No significant differences were detected between the wave (12 \pm 6.8 gammarids suspended) and the pause phases $(8.3 \pm 6.9$ in the pause phase, $t$ test, $P=0.419)$ of the pulse wave treatment. The continuous wave treatment resulted in an intermediate number of detached gammarids (Fig. 1).

\section{Impact of waves on predators}

Significant differences in the number of foraged gammarids among fish types and wave treatments were found (Table 1). Both D0 and D1 consumed significantly more gammarids in the pulse wave treatment than in the continuous wave or the control treatments (Fig. 2a, b). While D0 tended to ingest fewer gammarids in the continuous wave treatment $(2.5 \pm 0.5$; mean $\pm \mathrm{SD})$ than in the control $(3.5 \pm 0.7), \mathrm{D} 1$ tended to consume more gammarids in the continuous wave treatment $(2.9 \pm 0.6)$ than in the control $(1.3 \pm 0.4)$ (Fig. 2a, b), but these differences were 


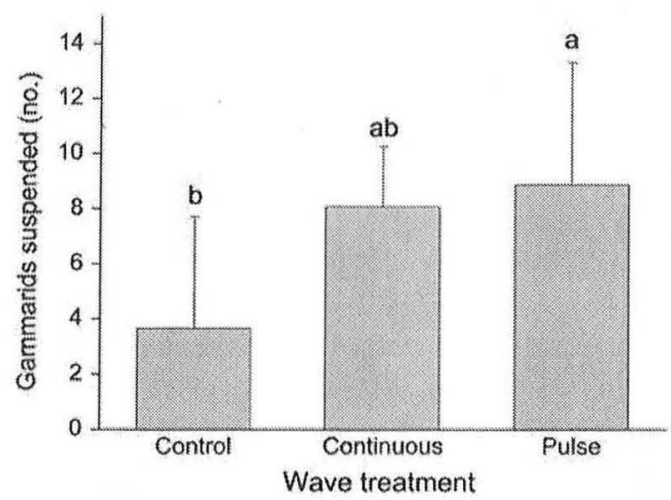

Fig. 1 Total numbers of gammarids (mean $+\mathrm{SD}$ ) suspended in the water column during the no-wave control, continuous wave and pulse wave treatments. Different letters indicate significant differences according to Student's post hoc tests $(P<0.05)$

Table 1 Differences in the number of foraged gammarids, swimming activity and foraging attempts among wave treatments and fish types

\begin{tabular}{lrrrr}
\hline Factor & $d f$ & \multicolumn{1}{l}{ SS } & \multicolumn{1}{l}{$F$} & \multicolumn{1}{l}{$P$} \\
\hline Foraged gammarids $\left(R^{2}=0.39\right)$ & & & & \\
Wave treatment & 2 & 275.3 & 15.15 & $<\mathbf{0 . 0 0 1}$ \\
Fish type & 2 & 77.5 & 4.27 & $<\mathbf{0 . 0 0 1}$ \\
Wave treatment $\times$ fish type & 4 & 373.9 & 10.28 & $<\mathbf{0 . 0 0 1}$ \\
Swimming activity $\left(R^{2}=0.64\right)$ & & & & \\
Wave treatment & 2 & 200.5 & 22.8 & $<\mathbf{0 . 0 0 1}$ \\
Fish type & 2 & 33.9 & 3.9 & $\mathbf{0 . 0 2 8}$ \\
Wave treatment $\times$ fish type & 4 & 19.0 & 4.3 & $\mathbf{0 . 0 0 5}$ \\
Foraging attempts $\left(R^{2}=0.47\right)$ & & & & \\
Wave treatment & 2 & 4.9 & 9.4 & $<\mathbf{0 . 0 0 1}$ \\
Fish type & 2 & 2.7 & 5.3 & $\mathbf{0 . 0 0 9}$ \\
Wave treatment $\times$ fish type & 4 & 2.7 & 0.7 & $\mathbf{0 . 0 4 6}$ \\
\hline
\end{tabular}

There were three wave treatments: no-wave control, continuous wave and pulse wave. There were three fish types: D0, D1 and B0. Twoway ANOVA was employed. Significant results $(P<0.05)$ are given in bold

not significant. B0 consumed significantly more gammarids in the control than in the continuous and pulse wave treatments (Fig. 2c), and no significant differences in foraging success were found between the continuous and pulse wave treatments.

Fish swimming activity differed significantly among fish types and treatments (Table 1). Swimming activity of D0 did not differ significantly among wave treatments (Table 2, Fig. 2d), but it did differ significantly among wave treatments for D1 and B0 (Table 2, Fig. 2e, f). D1 individuals were least active in the control and most active in the pulse wave treatment. Intermediate activities were recorded in the continuous wave treatment (Fig. 2e). There were no significant differences between the two phases of the pulse wave treatment (Table 3). B0 individuals were significantly more active during the pulse wave treatment than during any other treatment (Fig. 2f). Considering the two phases of the pulse wave treatment separately, B0 was significantly more active in the pause phase than in the wave phase (Table 3 ). The activity in the pause phase even exceeded the activity in any other treatment. The lowest B0 activity level was recorded in the continuous wave treatment (Fig. 2f).

Foraging attempts differed significantly among fish types and wave treatments, and significant interactions between wave treatments and fish types were also found (Table 1). Foraging attempts varied significantly among the wave treatments for D1 and B0 but not for DO (Table 2, Fig. 2g-i). However, D0 made significantly more foraging attempts during the wave phase than during the pause phase of the pulse wave treatment (Table 3). For D1, the number of foraging attempts was significantly higher in the continuous wave treatment than in the pulse wave treatment or in the control (Fig. 2h). B0 had significantly more foraging attempts in the control and continuous wave treatment than in the pulse wave treatment (Fig. 2i).

\section{Discussion}

Impact of waves on prey

In accordance with our first hypothesis, waves increased the number of gammarids suspended in the water column, which left them more exposed to predation. The pulse wave treatment resulted in more suspended gammarids than in the continuous wave treatment. Thus, gammarid detachment was not only caused by wave intensity, which was similar among the wave treatments, but also by the discontinuity of the disturbance. When exposed to waves, gammarids hid between pebbles to minimize hydrodynamic exposure and reduce the risk of being suspended. In the continuous wave treatment, the gammarids remained hidden. In the pulse wave treatment, gammarids left their shelters during wave pause phases, leaving them exposed and unprepared when the next wave occurred. The observed number of suspended gammarids did not change during the pulse wave treatment, suggesting that individuals did not acclimate to the repeated disturbance. Moreover, we observed that individuals remained suspended after the end of the pulse waves.

At orbital wave velocities of $18 \mathrm{~cm} \mathrm{~s}^{-1}$ (corresponding to waves generated by small recreational boats; Gabel, unpublished data), about $10 \%$ of the gammarids were suspended. Comparable detachment rates were recorded in a smaller experimental wave tank (Gabel et al. 2008) and under field conditions (unpublished data) at the same wave velocity. Similarly, Bishop (2008) showed that experimental ship waves dislodged invertebrates from seagrass 
Dace age-0
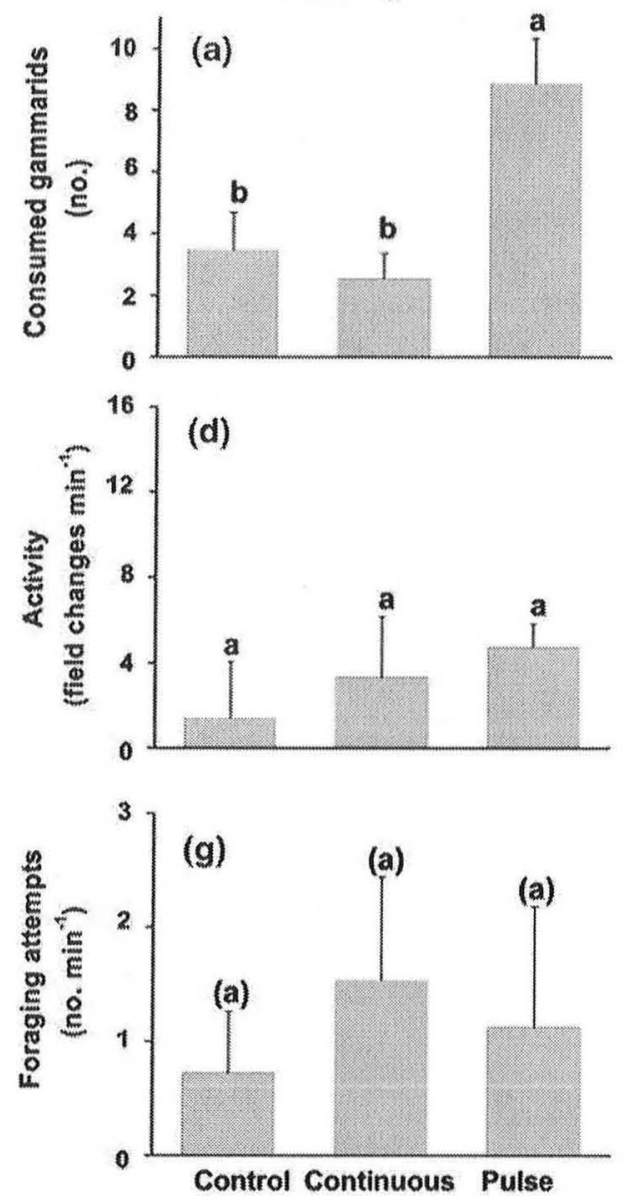

Dace age-1

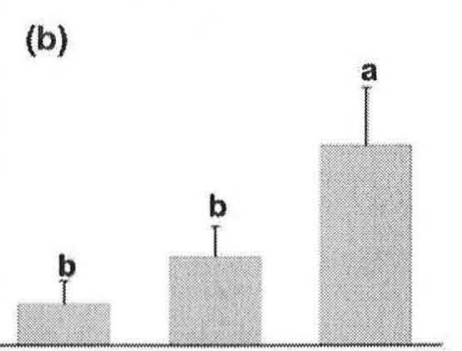

(e)

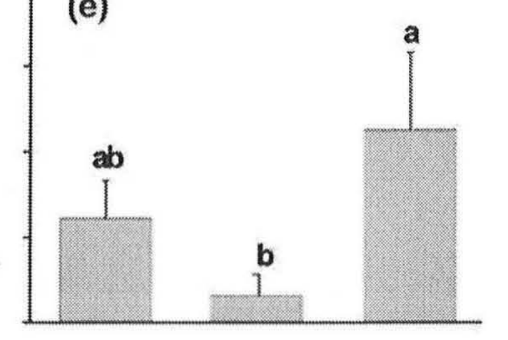

(h)

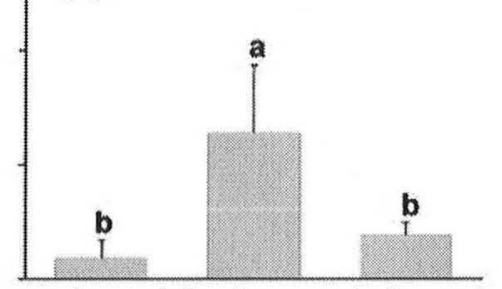

Control Continuous Pulse Wave treatment
Bream age -0

(c)

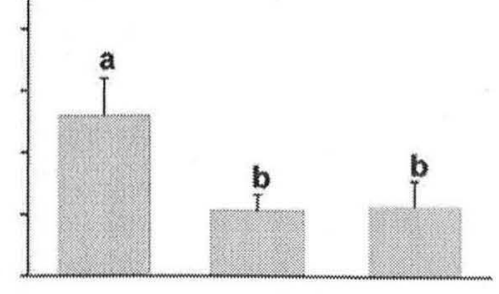

(f)

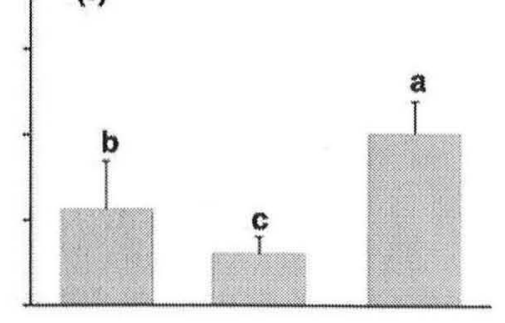

(i)

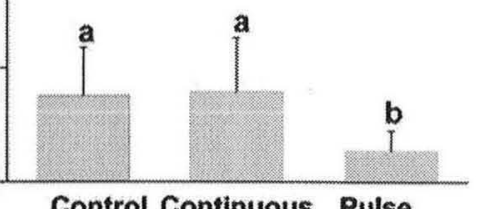

Control Continuous Pulse
Fig. 2 Number of consumed gammarids, fish swimming activity, and number of attempts to capture prey per individual of age- 0 dace (D0), age- 1 dace (D1) and age- 0 bream (B0) $($ mean + SD) in no-wave

blades. Hence, our results suggest that even ship-induced waves of low kinetic energy significantly increase the risk of predation on benthic invertebrates with limited attachment capabilities.

Impact of waves on predators

In agreement with hypothesis two, smaller fusiform fish perform better under waves than larger or deep-bodied fish. Dace showed significantly higher foraging success in the pulse wave treatment than in the continuous wave treatment, indicating that dace mainly catch prey items during pauses in-between wave pulses. Under continuous waves, both dace and detached gammarids were constantly shifted around, reducing the snapping accuracy of the predators and potentially leading to the high number of foraging attempts seen under continuous waves, as not every attempt control, continuous, and pulse wave treatments. Different letters indicate significant differences according to Student's post hoc tests $(P<0.05)$

may be successful. In contrast, calm conditions during the wave pauses of the pulse waves allowed for more precise snapping. The number of foraging attempts observed was lower during pause phases, probably because the dace required time to finish with the prey after each successful catch before they continued foraging (Holling 1959). While D0 foraging success slightly decreased under continuous waves compared to the control, larger D1 individuals showed increased foraging success. This difference could result from the higher body strength and manoeuvrability of the larger D1 individuals, which could lead to more precise snapping even under continuous waves. However, the high foraging success and relatively stable swimming activities of smaller dace under pulse waves indicate that age- 0 dace can cope efficiently with wave-induced hydrodynamic disturbances and even profit from the increased food accessibility. It is also known that age- 0 dace and 
Table 2 Differences in foraging success, swimming activity, and foraging attempts among the different wave treatments for the three types of fish: age- 0 dace (D0), age-1 dace (D1), and age-0 bream (B0)

\begin{tabular}{llrrr}
\hline Type of fish & $d f$ & \multicolumn{1}{l}{ SS } & \multicolumn{1}{l}{$F$} & \multicolumn{1}{l}{$P$} \\
\hline Foraging success & & & & \\
D0 & 2 & 70.1 & 24.1 & $\mathbf{0 . 0 0 1}$ \\
D1 & 2 & 41.7 & 12.1 & $\mathbf{0 . 0 0 8}$ \\
B0 & 2 & 18.0 & 11.3 & $\mathbf{0 . 0 0 9}$ \\
Swimming activity & & & & \\
D0 & 2 & $3,663.0$ & 11.6 & $\mathbf{0 . 1 2 4}$ \\
D1 & 2 & $27,366.8$ & 61.3 & $<\mathbf{0 . 0 0 1}$ \\
B0 & 2 & $16,419.5$ & 41.6 & $<\mathbf{0 . 0 0 1}$ \\
Foraging attempts & & & & \\
D0 & 2 & 2.2 & 1.5 & $\mathbf{0 . 2 5 7}$ \\
D1 & 2 & 4.6 & 19.2 & $<\mathbf{0 . 0 0 1}$ \\
B0 & 2 & 1.3 & 4.7 & $\mathbf{0 . 0 2 2}$ \\
\hline
\end{tabular}

One way ANOVA was employed. Significant results $(P<0.05)$ are given in bold

Table 3 Differences in swimming activity and foraging attempts between the wave phase and the pause phase of the pulse wave treatment for the three types of fish: age- 0 dace (D0), age-1 dace (D1), and age- 0 bream (B0)

\begin{tabular}{lllr}
\hline Fish type & Wave phase & Pause phase & $P$ \\
\hline \multicolumn{2}{l}{ Swimming activity } & & \\
D0 & $5.1 \pm 2.0$ & $4.6 \pm 0.9$ & 0.706 \\
D1 & $7.8 \pm 3.3$ & $9.4 \pm 4.9$ & 0.732 \\
B0 & $3.6 \pm 0.9$ & $9.5 \pm 1.9$ & $<\mathbf{0 . 0 0 1}$ \\
Foraging attempts & & \\
D0 & $2.6 \pm 2.2$ & $0.6 \pm 0.7$ & $\mathbf{0 . 0 0 6}$ \\
D1 & $0.7 \pm 0.3$ & $0.3 \pm 0.1$ & 0.219 \\
B0 & $0.3 \pm 0.2$ & $0.3 \pm 0.2$ & 0.536 \\
\hline
\end{tabular}

This separation was not feasible for foraging success, as gut contents were analyzed at the end of the trials. $t$ tests were employed. Significant results $(P<0.05)$ are given in bold

other juvenile fusiform fishes prefer wave-exposed shallow littoral habitats $(<50 \mathrm{~cm}$ deep, Fischer and Eckmann 1997), and that pulse waves led to increased somatic growth in these fishes (Stoll and Fischer 2010; Stoll et al. 2010). Larger dace also increased ingestion rates in the pulse waves, but they also increased the energy they expended in activities. Posture stability is directly related to swimming speed in fish (Weihs 1993), which becomes increasingly important as the body size of the fish increases, as it gains more momentum when seized by waves (Webb 2002). Higher levels of swimming activity and higher energetic costs of posture control are supposed to increase the total energy expended on activities in the fish type represented by D1. In the pulse wave treatment, these costs can even outweigh the benefits of increased foraging success, as these fish grew less in the pulse wave treatment compared to the control (Stoll and Fischer 2010).

B0 did not benefit from either wave treatment. Despite the increased prey availability during wave treatments, B0 had the lowest foraging success. In the wave treatments, foraging attempts and swimming activities were similar or lower than those of the control, except for a significant increase in swimming activity recorded during the pause phase of the pulse wave treatment. Despite an increase in swimming activity, the number of foraging attempts remained low. Thus, this increase in swimming activity was probably a manoeuvre to escape the exposed area before the next wave pulse. Concordantly, B0 individuals exposed to pulse waves showed reduced somatic growth (Stoll and Fischer 2010). In lakes, bream leave the shallow littoral zone and move to deeper zones in the middle of their first summer when they become deep-bodied (Fischer and Eckmann 1997).

Finally, the third hypothesis (ship-induced waves have a stronger impact on the prey-predator interaction than wind waves in a given time interval) was also verified. Pulse waves caused more resuspension of gammarids, and feeding success of dace was increased, while it was not in the continuous wave treatment. Bream also changed its swimming activity more drastically in the pulse wave treatment than in the continuous wave treatment in comparison to the control.

These results show how wind- and ship-induced waves affect predator-prey interactions. Waves increase prey accessibility but only favour fish species with body shapes that allow them to cope with a harsh hydraulic environment. Moreover, the benefit to individual growth results from a balance between energy intake and energy cost of hunting activity, which appears to be positive only for young fusiform fish, as represented in our experiments by age- 0 dace.

Predator-prey interactions and consequences at higher levels of organisation

Predators and prey responded differently to wave disturbances, and the final effect on the predator-prey interaction depended on how both coped with this stress. When prey is more disturbed than the predator, such as in the gammaridD0 interaction, the waves are beneficial for the predators. However, when the predator is more affected than the prey, such as in the gammarid-B0 interaction, predation was hampered by waves. In the case of D1, the overall effect of waves on predator-prey interaction was not that clear. Although D1 exerted increased foraging pressure on gammarids in the pulse wave treatment, they grew less because of higher activity costs (Stoll and Fischer 2010). Hence, a predator like D1 does not seem to be able to profit from waves in the long term. However, fish are known to 
take advantage of different habitats for different ecological purposes (Neverman and Wurtsbaugh 1994; Sims et al. 2006). Hence, by foraging at wave-exposed sites, but resting in calm waters, predators like D1 might still benefit from waves.

Besides the direct effects on predator and prey behaviour, waves can also indirectly effect predator-prey interactions by changing predator-predator competition. Under ship-induced disturbance, invertebrates with low fixing or burying capabilities have an increased risk of predation. In these circumstances, both invertebrate abundance and species diversity are likely to be reduced. Accordingly, invertebrate species with better hiding capabilities will better cope with wave disturbance and resulting predation. These changes in intra-guild competitiveness and predation pressure will ultimately result in shifts in species composition.

Predator-prey interactions were more strongly affected by ship-induced waves (pulse waves) than wind waves (continuous waves). As a consequence, ship-induced waves are expected to cause more pronounced shifts in the community composition of fish and invertebrates inhabiting littoral habitats than wind waves. In navigational canals, fish species that cannot cope with hydrodynamic stress were shown to be excluded from areas near shipping routes (Arlinghaus et al. 2002; Wolter and Arlinghaus 2003). Changes in littoral invertebrate communities due to wave exposure at wind-exposed shores of lakes (Barton and Carter 1982) and due to ship-induced waves (Bishop and Chapman 2004) have been shown. However, under natural conditions, wind-induced waves generally occur over longer periods than ship-induced waves, such that in littoral areas that are frequently exposed to wind but rarely to ship waves, wind waves may be ecologically more relevant than ship-induced waves.

Our experimental setup did not control for other environmental conditions induced by waves that may possibly influence predator-prey relationships. In our experiments we used sand and gravel as substrates, as they are the common substrates at Lake Constance (Mörtl and Rothhaupt 2003) and other large lakes.

However, structurally complex habitats in the littoral zone may mitigate the wave effects described above. Complex habitats, such as scoured tree roots or dense reed belts, reduce the susceptibility to predation (Warfe and Barmuta 2004, 2006; but see Mattila et al. 2008) and dissipate the kinetic energy of the hydrodynamic disturbance (Borchardt 1993; Gabel et al. 2008). Thus, in structurally diverse littoral habitats, invertebrate densities may not be as strongly affected by the increased predation rate. To avoid shifts in littoral food webs, the management of shores exposed to ship-induced waves should focus on preserving complex habitat structures and reducing shore exposure to waves.
Acknowledgments We thank $\mathrm{M}$. Wolf for his technical support and T. Hintze for his assistance with video equipment. The manuscript benefited from the comments of K. Tockner, T. Mehner, C. Wolter, M. Brauns and two anonymous reviewers. This study was completed within the Collaborative Research Centre 454, "Littoral Zone of Lake Constance", and was financed by the German Research Foundation (DFG), the German Federal Environmental Foundation (F. Gabel) and the German National Academic Foundation (S. Stoll).

\section{References}

Arlinghaus R, Engelhardt C, Sukhodolov A, Wolter C (2002) Fish recruitment in a canal with intensive navigation: implications for ecosystem management. J Fish Biol 61:1386-1402. doi:10.1006/ jfbi.2002.2148

Backiel T, Zawiska J (1968) Synopsis of biological data on the bream, Abramis brama L. Rom. FAO Fish Biol Synopsis 36:1-120

Barton DR, Carter JCH (1982) Shallow-water epilithic invertebrate communities of eastern Georgian Bay, Ontario, in relation to exposure to wave action. Can J Zool 60:984-993

Bishop MJ (2008) Displacement of epifauna from seagrass blades by boat wake. J Exp Mar Biol Ecol 354:111-118. doi:10.1016/j.jembe. 2007.10.013

Bishop MJ, Chapman MG (2004) Managerial decisions as experiments: an opportunity to determine the ecological impact of boat-generated waves on macrobenthic infauna. Estuar Coast Shelf Sci 61:613-622. doi:10.1016/j.ecss.2004.06.023

Blanchet S, Loot G, Dodson JJ (2008) Competition, predation and flow rate as mediators of direct and indirect effects in a stream food chain. Oecologia 157:93-104. doi:10.1007/s00442-0081044-8

Borchardt D (1993) Effects of flow and refugia on drift loss of benthic macroinvertebrates - implications for habitat restoration in lowland streams. Freshw Biol 29:221-227

Bryazgunova MI (1979) Feeding relationships of the young of the pike perch, Lucioperca lucioperca, the bream, Abramis brama, and fishes of lesser importance in the lower reaches of the Don. J Ichthyol 19:57-65

Commito JA, Thrush SF, Pridmore RD, Hewitt JE, Cummings VJ (1995) Dispersal dynamics in a wind-driven benthic system. Limnol Oceanogr 40:1513-1518

Crowden AE, Broom DM (1980) Effects of the eyefluke, Diplostomum spathaceum, on the behavior of dace (Leuciscus leuciscus). Anim Behav 28:287-294

Elliott JM (1973) Food of brown and rainbow trout (Salmo trutta and S. gairdneri) in relation to abundance of drifting invertebrates in a mountain stream. Oecologia 12:329-347

Fischer P, Eckmann R (1997) Spatial distribution of littoral fish species in a large European lake, Lake Constance. Ger Arch Hydrobiol 140:91-116

Gabel F, Garcia X-F, Brauns M, Sukhodolov A, Leszinski M, Pusch MT (2008) Resistance to ship-induced waves of benthic invertebrates in various littoral habitats. Freshw Biol 53:1567-1578. doi:10.1111/j.1365-2427.2008.01991.x

Goldspink CR (1978) The population density, growth rate and production of bream, Abramis brama, in Tjeukemeer, the Netherlands. J Fish Biol 13:499-517

Hart DD, Finelli CM (1999) Physical-biological coupling in streams: the pervasive effects of flow on benthic organisms. Annu Rev Ecol Syst 30:363-395

Hart DD, Merz RA (1998) Predator prey interactions in a benthic stream community: a field test of flow-mediated refuges. Oecologia 114:263-273 
Hellawell JM (1974) The ecology of populations of dace Leuciscus leuciscus (L.), from two tributaries of the River Wye, Herefordshire, England. Freshw Biol 4:577-604

Hine PM, Kennedy CR (1974) The population biology of the acanthocephalan Pomphorhynchus laevis (Miiller) in the River Avon. J Fish Biol 6:665-679

Hofmann H, Lorke A, Peeters F (2008) The relative importance of wind and ship waves in the littoral zone of a large lake. Limnol Oceanogr 53:368-380

Holling CS (1959) Some characteristics of simple types of predation and parasitism. Can Entomol 91:385-398

Kottelat M, Freyhof J (2007) Handbook of European freshwater fishes. Publications Kottelat, Cornol

Macan TT (1977) The influence of predation on the composition of fresh-water animal communities. Biol Rev 52:45-70

Malmqvist B, Sackmann G (1996) Changing risk of predation for a filter-feeding insect along a current velocity gradient. Oecologia 108:450-458

Mattila J, Heck KL, Millstein E, Miller E, Gustafsson C, Williams S, Byron D (2008) Increased habitat structure does not always provide increased refuge from predation. Mar Ecol Prog Ser 361:15-20. doi:10.3354/meps07392

Mörtl M, Rothhaupt KO (2003) Effects of adult Dreissena polymorpha on settling juveniles and associated macroinvertebrates. Int Rev Hydrobiol 88:561-569. doi: 10.1002/iroh.200310640

Neverman D, Wurtsbaugh WA (1994) The thermoregulatory function of diel vertical migration for a juvenile fish, Cottus extensus. Oecologia 98:247-256

Palmer MA (1988) Epibenthic predators and marine meiofaunaseparating predation, disturbance, and hydrodynamic effects. Ecology 69:1251-1259

Peckarsky BL, Horn SC, Statzner B (1990) Stonefly predation along a hydraulic-gradient-a field-test of the harsh benign hypothesis. Freshw Biol 24:181-191

Powers SP, Kittinger JN (2002) Hydrodynamic mediation of predator-prey interactions: differential patterns of prey susceptibility and predator success explained by variation in water flow. $\mathrm{J}$ Exp Mar Biol Ecol 273:171-187

Scheifhacken N (2006) Life at turbulent sites. Benthic communities in lake littorals interacting with abiotic and biotic constraints (Ph.D. thesis). Univ. of Constance, Constance

Schofield DK, Townsend CR, Hildrew AG (1988) Predation and the prey community of a headwater stream. Freshw Biol 20:85-95

Sih A, Crowley P, Mcpeek M, Petranka J, Strohmeier K (1985) Predation, competition, and prey communities-a review of field experiments. Ann Rev Ecol Syst 16:269-311
Sims DW, Wearmouth VJ, Southall EJ, Hill JM, Moore P, Rawlinson K, Hutchinson N, Budd GC, Righton D, Metcalfe JD, Nash JP, Morritt D (2006) Hunt warm, rest cool: bioenergetic strategy underlying diel vertical migration of a benthic shark. J Anim Ecol 75:176-190. doi:10.1111/j.1365-2656.2005.01033.x

Starry O, Wanzenböck J, Danielopol DL (1998) Tendency of the amphipod Gammarus roeseli Gervais to colonize coarse sediment habitats under fish predation pressure. Int Rev Hydrobiol 83:371-380

Stoll S, Fischer P (2010) Three different patterns of how low-intensity waves can affect the energy budget of littoral fish: a mesocosm study. Oecologia. doi:10.1007/s00442-010-1793-z

Stoll S, Fischer P, Klahold P, Scheifhacken N, Hofmann H, Rothhaupt KO (2008) Effects of water depth and hydrodynamics on the growth and distribution of juvenile cyprinids in the littoral zone of a large pre-alpine lake. J Fish Biol 72:1001-1022. doi: 10.1111/j.1095-8649.2007.01780.x

Stoll S, Hofmann H, Fischer P (2010) Effect of wave exposure dynamics on gut content mass and growth of young-of-the-year fishes in the littoral zone of lakes. J Fish Biol 76:1714-1728

Warfe DM, Barmuta LA (2004) Habitat structural complexity mediates the foraging success of multiple predator species. Oecologia 141:171-178. doi:10.1007/s00442-004-1644-x

Warfe DM, Barmuta LA (2006) Habitat structural complexity mediates food web dynamics in a freshwater macrophyte community. Oecologia 150:141-154. doi:10.1007/s00442-0060505-1

Weatherley NS (1987) The diet and growth of 0-group dace Leucicus leuciscus (L.), and roach, Rutilus rutilus (L.), in a lowland river. J Fish Biol 30:237-247

Webb PW (2002) Control of posture, depth and swimming trajectories of fishes. Integr Comp Biol 42:94-101

Weihs D (1993) Stability of aquatic animal locomotion. Contemp Math 141:443-461

Winnell MH, Jude DJ (1991) Northern large-river benthic and larval fish drift-St Marys River, USA/Canada. J Great Lakes Res 17:168-182

Wolter C, Arlinghaus R (2003) Navigation impacts on freshwater fish assemblages: the ecological relevance of swimming performance. Rev Fish Biol Fish 13:63-89

Wolter C, Arlinghaus R, Sukhodolov A, Engelhardt C (2004) A model of navigation-induced currents in inland waterways and implications for juvenile fish displacement. Environ Manage 34:656-668. doi:10.1007/s00267-004-0201-z 